\title{
Giant negative linear compressibility in zinc dicyanoaurate
}

\section{SUPPLEMENTARY INFORMATION}

Andrew B. Cairns, ${ }^{1}$ Jadna Catafesta, ${ }^{2,3}$ Claire Levelut, ${ }^{3}$ Jérôme Rouquette, ${ }^{2}$ Arie van der Lee, ${ }^{4}$ Lars Peters, ${ }^{5}$ Amber L. Thompson, ${ }^{1}$ Vladimir Dmitriev, ${ }^{6}$ Julien Haines, ${ }^{2}$ and Andrew L. Goodwin ${ }^{1 *}$

${ }^{1}$ Department of Chemistry, University of Oxford, Inorganic Chemistry Laboratory, South Parks Road, Oxford OX1 3QR, U.K.

${ }^{2}$ Institut Charles Gerhardt, Équipe C2M, UMR-CNRS 5253, Université Montpellier 2,

Place E. Bataillon, 34095 Montpellier Cedex 5, France

${ }^{3}$ Laboratoire Charles Coulomb, UMR-CNRS 5221, Université Montpellier 2,

Place E. Bataillon, 34095 Montpellier Cedex 5, France

${ }^{4}$ Institut Européen des Membranes de Montpellier, UMR-CNRS 5635, Université Montpellier 2, 300 Avenue Prof. E. Jeanbrau, 34095 Montpellier, Cedex 5, France

${ }^{5}$ Institut für Kristallographie, RWTH Aachen, Jaegerstrasse 17-19, 52066 Aachen, Germany ${ }^{6}$ SNBL at ESRF, Polygone Scientifique Louis Néel, 6 rue Jules Horowitz, 38000 Grenoble, France

*To whom correspondence should be addressed; E-mail: andrew.goodwin@chem.ox.ac.uk.

\section{Submitted to Nature Materials}




\section{Contents}

1 Materials and Methods 3

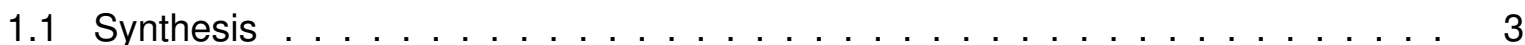

1.2 Variable pressure single crystal X-ray diffraction . . . . . . . . . . . . . . . 3

1.3 Variable temperature single crystal X-ray diffraction . . . . . . . . . . . . . . . . 3

1.4 Variable pressure powder X-ray diffraction . . . . . . . . . . . . . . . . 4

1.5 Spectroscopy . . . . . . . . . . . . . . . . . . . . 4

2 Geometric Description of the $\mathrm{Zn}\left[\mathrm{Au}(\mathrm{CN})_{2}\right]_{2}$ Structure 5

3 Crystallographic Analysis of Single-Crystal X-Ray Diffraction Data 7

3.1 Phase I: Variable-pressure structure refinements . . . . . . . . . . . 7

3.2 Phase I: Variable-temperature structure refinements . . . . . . . . . . . . . . . 9

3.3 The $1.8 \mathrm{GPa}$ phase $\mathrm{I} / \mathrm{ll}$ transition . . . . . . . . . . . . . . . . . . . 11

3.4 Phase II: Variable-pressure structure refinements . . . . . . . . . . . . . . . . . 13

4 Crystallographic Analysis of Powder X-ray Diffraction Data 17

5 Compressibilities and Equations of State 21

5.1 Approach . . . . . . . . . . . . . . . . . . . 21

5.2 Experimental compressibility fitting . . . . . . . . . . . . . . . . . . 21

5.3 Equation of state fitting . . . . . . . . . . . . . . . . . . . . 24

6 Geometric Considerations of NLC in Uniaxial Networks 26

7 Raman Spectroscopic Analysis $\quad 30$

8 References 32 


\section{Materials and Methods}

\subsection{Synthesis}

All reagents were obtained from commercial suppliers and used as supplied. Suitable precautions were observed when handling cyanides.

Large single crystals of zinc dicyanoaurate were prepared hydrothermally. Aqueous solutions of $\mathrm{Zn}\left(\mathrm{CH}_{3} \mathrm{COO}\right)_{2} \cdot 2 \mathrm{H}_{2} \mathrm{O}$ (Sigma Aldrich, $98 \%, 14 \mathrm{mg}$ ) and $\mathrm{KAu}(\mathrm{CN})_{2}$ (Sigma Aldrich, $98 \%$, $60 \mathrm{mg}$ ) were combined in a teflon-lined Parr reaction vessel $(23 \mathrm{~mL}$ capacity; $10 \mathrm{~mL}$ total solution volume). The vessel was sealed and heated to $120^{\circ} \mathrm{C}$ for $2 \mathrm{~h}$, and then cooled slowly to room temperature at a rate of $1^{\circ} \mathrm{Ch}^{-1}$. The resulting reaction mixture contained large single crystals of $\mathrm{Zn}\left[\mathrm{Au}(\mathrm{CN})_{2}\right]_{2}$ (19.9 mg; $\left.54.1 \%\right)$, which formed as colourless bicapped hexagonal prisms. This morphology was consistent with the $\alpha$-polymorph of $\mathrm{Zn}\left[\mathrm{Au}(\mathrm{CN})_{2}\right]_{2}$ described previously. ${ }^{\mathrm{S} 1}$ All studies reported in this manuscript made use of single crystals obtained from a single hydrothermal preparation as described above.

\subsection{Variable pressure single crystal X-ray diffraction}

Variable-pressure single-crystal X-ray diffraction measurements were performed using a Agilent Gemini Diffractometer equipped with a Sapphire CCD detector (sample-detector distance $65.00 \mathrm{~mm})$. A single crystal $(0.050 \mathrm{~mm} \times 0.050 \mathrm{~mm} \times 0.065 \mathrm{~mm})$, prepared as described above, was loaded in a tungsten gasket between the anvils of a Merrill-Bassett diamond anvil cell. A single chip of ruby was included for pressure calibration, and Daphne 7474 oil was used as the pressure transmitting medium. ${ }^{S 2}$ Data collection, indexing and reduction were performed using CrysAlis Pro (Agilent). Data were corrected for absorption using Absorb 6.0; 33 merging of the data and outlier rejection was performed using the Average 2.22 software. ${ }^{54}$ Structure refinements were performed using SHELXL97. ${ }^{55}$ The structure of the high-pressure phase $\mathrm{Zn}\left[\mathrm{Au}(\mathrm{CN})_{2}\right]_{2}-$ II was solved by direct methods using SHELXD, ${ }^{\mathrm{S}}$ having established the appropriate space group $\mathrm{P}_{4} 22$ on the basis of the observed $(00 l)$ reflection condition. Additional atom positions were located using difference Fourier maps. The $\mathrm{C}-\mathrm{N}$ distance was constrained in all refinements, making use of the average value determined in the ambientpressure $\mathrm{Zn}\left[\mathrm{Au}(\mathrm{CN})_{2}\right]_{2}-\mathrm{I}$ phase. Due to the large number of variables for the high pressure phase, the $\mathrm{Au}-\mathrm{C}$ and $\mathrm{Zn}-\mathrm{N}$ distances were also constrained; thermal similarity constraints were applied to a subset of the $\mathrm{C}$ and $\mathrm{N}$ atom pairs; all $\mathrm{C}$ and $\mathrm{N}$ atoms were treated using isotropic displacement parameters as were the $\mathrm{Zn}$ atoms in the high-pressure phase.

\subsection{Variable temperature single crystal X-ray diffraction}

Variable-temperature single crystal X-ray diffraction measurements were carried out using an Oxford Diffraction (Agilent) SuperNovae diffractometer (graphite-monochromated Mo K $\alpha$ radiation, $\lambda=0.71073 \AA$ ) fitted with an Oxford Cryosystems cryostream. ${ }^{\mathrm{S} 6}$ A small crystal $(0.106 \mathrm{~mm}$ $\times 0.130 \mathrm{~mm} \times 0.21 \mathrm{~mm}$ ) was mounted on a glass fibre using nail varnish as a fixing agent. On cooling from 300 to $100 \mathrm{~K}$, a series of $\omega$-scans were carried out at equally-spaced intervals of $50 \mathrm{~K}$, giving a maximum resolution of $0.77 \AA$ as determined by Chrysalis Pro (Agilent). Complete data sets were collected at intervals of $50 \mathrm{~K}$ on cooling from 300 to $100 \mathrm{~K}$, at intervals of $20 \mathrm{~K}$ on heating from 100 to $400 \mathrm{~K}$, and finally at intervals of $50 \mathrm{~K}$ on cooling from 400 
to $300 \mathrm{~K}$. Data indexing, reduction and Gaussian absorption correction were performed using CrysAlisPro (Agilent) and structures were solved using SIR92 within CRYSTALS. ${ }^{\text {S7, S8 }}$ Direct methods were used to solve all structures independently. A four-parameter Chebychev polynomial weighting scheme was used to optimise weights in all cases. ${ }^{\mathrm{S} 9}$ The Flack $x$ parameter was refined in all cases giving a value close to 0 with a standard uncertainty of 0.03 in each case, suggesting that the crystal studied was a single enantiomer. ${ }^{S 10,} \$ 11$

\subsection{Variable pressure powder X-ray diffraction}

A small collection of single crystals of $\mathrm{Zn}\left[\mathrm{Au}(\mathrm{CN})_{2}\right]_{2}$ were ground to a very fine powder and placed in the cavity of stainless steel gasket of an ETH diamond anvil cell. A single ruby sphere was placed in the gasket for pressure calibration using ruby fluorescence detection method, ${ }^{\mathrm{S} 12}$ and Fluorinert FC-77 was used as the pressure transmitting medium. Data were collected at beamline BM01A (Swiss-Norwegian beamline) at the ESRF at room temperature. A wavelength of $0.69412 \AA$ was selected using a $\mathrm{Si}(111)$ monochromator with a focused beam-size of $0.1 \mathrm{~mm}$ $\times 0.1 \mathrm{~mm}$. Data were collected using the mar345 image plate with an approximate sample-todetector distance of $250 \mathrm{~mm}$. Calibration and subsequent integration was carried out using FIT2D. ${ }^{\mathrm{S} 13, \mathrm{~S} 14}$ Rietveld refinement was carried out using TOPAS Academic. ${ }^{\mathrm{S} 15}$

\subsection{Spectroscopy}

Variable-pressure Raman spectroscopy experiments were performed using a Membrane diamond anvil cell mounted on a Jobin-Yvon T64000 spectrometer. The $676.4 \mathrm{~nm}$ line of a $\mathrm{Kr}^{+}$ laser was used for excitation. The sample was loaded in the cavity of a stainless steel gasket, together with a single ruby chip as pressure-calibrant and glycerol as a pressure-transmitting medium. 


\section{Geometric Description of the $\mathrm{Zn}\left[\mathrm{Au}(\mathrm{CN})_{2}\right]_{2}$ Structure}

The crystal structure of $\mathrm{Zn}\left[\mathrm{Au}(\mathrm{CN})_{2}\right]_{2}$ consists of six interpenetrating $\beta$-quartz-like networks. Each net has $\mathrm{Zn}^{2+}$ centres as its tetrahedral nodes; these are connected via almost-linear dicyanoaurate $(-\mathrm{N}-\mathrm{C}-\mathrm{Au}-\mathrm{C}-\mathrm{N}-)$ linkers, which function geometrically as the framework edges. The similarity to $\beta$-quartz itself is straightforward: $\mathrm{Zn}^{2+}$ ions assume the crystallographic sites of $\mathrm{Si}^{4+}$ ions, and [NC-Au-CN] ${ }^{-}$ions the sites of $\mathrm{O}^{2-}$ ions. There is a single $\mathrm{Zn}$ atom and one [NC-Au-CN] moiety in the asymmetric unit of the crystallographic unit cell. Like $\beta$-quartz itself, $\mathrm{Zn}\left[\mathrm{Au}(\mathrm{CN})_{2}\right]_{2}$ crystallises in either one of the two enantiomorphic space groups $P 6_{2} 22 / P 6_{4} 22$. Each of the six interpenetrating quartz-like nets shares the same handedness, so crystals of $\mathrm{Zn}\left[\mathrm{Au}(\mathrm{CN})_{2}\right]_{2}$ are homochiral. This chirality is manifest in the structure in the presence of a number of helical structural motifs. One such motif concerns the Au. . Au interactions as discussed in the main text; these run parallel to the $\langle 100\rangle$ crystal axes and hence lie perpendicular to the unique (hexagonal) crystal axis. A second motif concerns the arrangement of dicyanoaurate linkers surrounding channels parallel to the hexagonal axis [Fig. S1].

At various points in the manuscript-as in section 6 below-reference is made to the "honeycomb"like nature of the $\beta$-quartz geometry adopted by $\mathrm{Zn}\left[\mathrm{Au}(\mathrm{CN})_{2}\right]_{2}$. This description refers in particular to the projection of the network viewed along the $\langle 110\rangle$ crystal axes [Fig. S2]. The

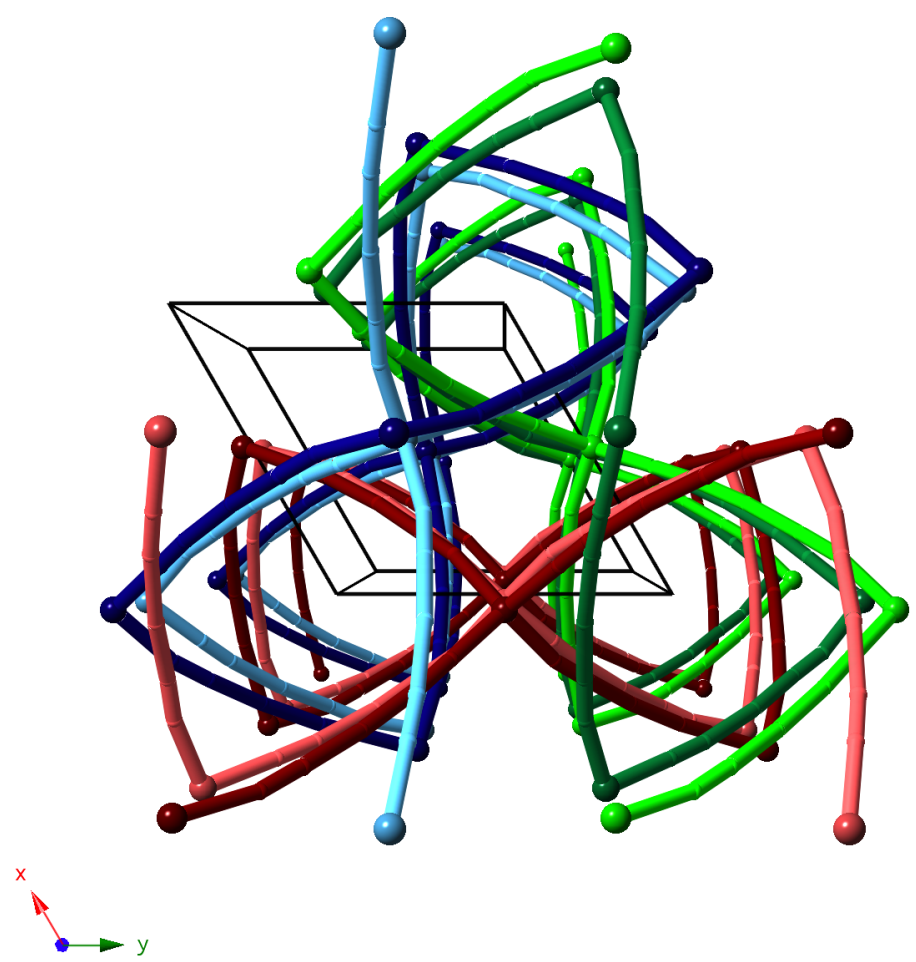

Figure S1: The six interpenetrating $\beta$-quartz nets of $\mathrm{Zn}\left[\mathrm{Au}(\mathrm{CN})_{2}\right]$ (shown here in various colours) form helical channels parallel to the c crystal axis. The handedness of these helices is determined by the space group chirality. 


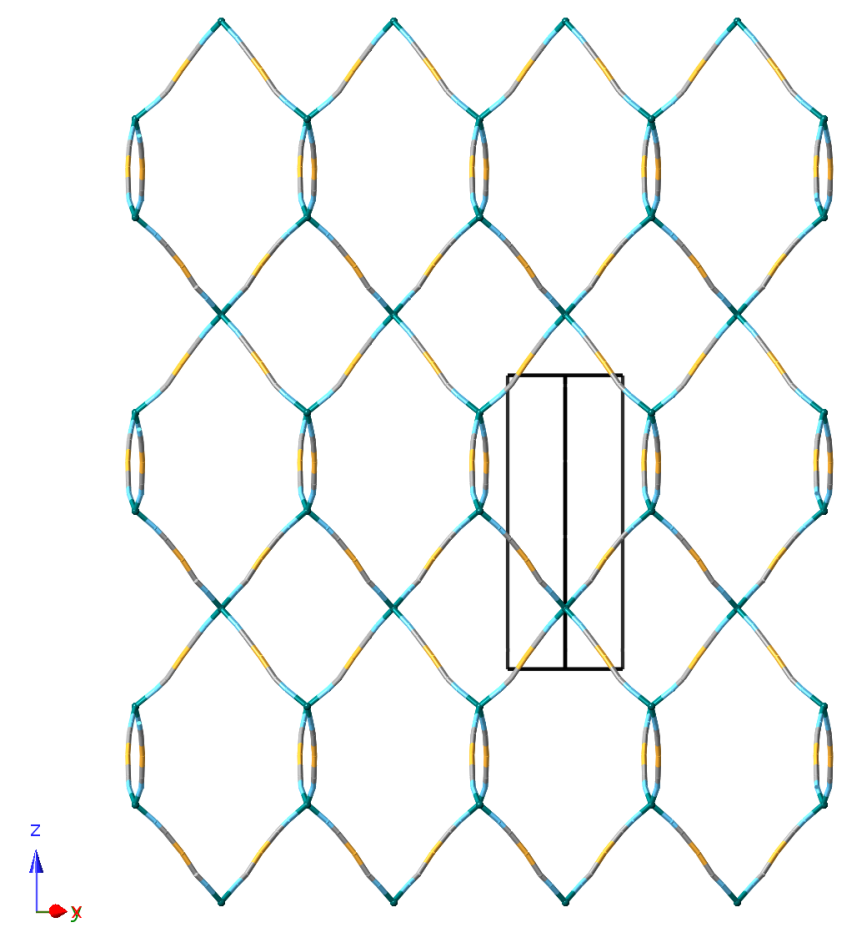

Figure S2: A projection of the structure of $\mathrm{Zn}\left[\mathrm{Au}(\mathrm{CN})_{2}\right]_{2}$ viewed along the $[110]$ crystal axis. Only one of the six interpenetrating nets is shown. The topology of the net shown in this projection is a hybrid of the honeycomb and wine-rack nets: rows of edge-sharing hexagons are connected vertically by rhombuses.

relationship between this projection and the honeycomb net is not exact: whereas in the latter the only ring type is hexagonal, in the former rows of connected hexagons are linked in a perpendicular direction by rhombuses. In this two-dimensional projection there appears to be two distinct types of network edge: those shared between a hexagon and a rhombus, and those shared only between a pair of hexagons. In practice, the three dimensional network contains only a single type of edge by virtue of the fact that rotation of the network structure amongst the various different symmetry-equivalent $\langle\overline{1} 10\rangle$ axes interchanges the hexagonal and rhombic units. 


\section{Crystallographic Analysis of Single-Crystal X-Ray Diffraction Data}

\subsection{Phase I: Variable-pressure structure refinements}

Key crystallographic details and structure refinement parameters for a single representative pressure value of $0.35(10) \mathrm{GPa}$ are given in Table S1. The evolution of lattice parameters and important structural features (bond lengths and bond angles) are summarised in Table S2.

Table S1: Representative single-crystal X-ray diffraction data collection and refinement details for $\mathrm{Zn}\left[\mathrm{Au}(\mathrm{CN})_{2}\right]_{2}-\mathrm{I}$ at $T=298 \mathrm{~K}$ and $p=0.35(10) \mathrm{GPa}$.

\begin{tabular}{|c|c|c|c|c|}
\hline Radiation & \multicolumn{4}{|c|}{ Mo $K \alpha, \lambda=0.71073 \AA$} \\
\hline Formula & \multicolumn{4}{|l|}{$\mathrm{ZnAu}_{2} \mathrm{C}_{4} \mathrm{~N}_{4}$} \\
\hline$M\left(\mathrm{~g} \mathrm{~mol}^{-1}\right)$ & \multicolumn{4}{|l|}{563.39} \\
\hline$Z$ & \multicolumn{4}{|l|}{6} \\
\hline Crystal Size (mm) & \multicolumn{4}{|c|}{$0.050 \times 0.050 \times 0.065$} \\
\hline Crystal System & \multicolumn{4}{|l|}{ Hexagonal } \\
\hline Space Group & \multicolumn{4}{|l|}{$P 6_{2} 22$} \\
\hline$a(\AA)$ & \multicolumn{4}{|l|}{$8.2549(7)$} \\
\hline$c(\AA)$ & \multicolumn{4}{|l|}{$21.1181(16)$} \\
\hline$V\left(\AA^{3}\right)$ & \multicolumn{4}{|l|}{$1246.27(17)$} \\
\hline$w R_{\mathrm{p}}\left(F^{2}\right)$ & \multicolumn{4}{|l|}{0.053} \\
\hline Flack parameter & \multicolumn{4}{|l|}{$-0.03(6)$} \\
\hline Atom & $x$ & $y$ & $z$ & $U_{\text {eq }}\left(\AA^{2}\right)$ \\
\hline $\mathrm{Zn}$ & -0.5000 & -0.5000 & $0.20664(16)$ & $0.0237(2)$ \\
\hline $\mathrm{Au}$ & $0.00203(18)$ & $0.31458(13)$ & $0.29248(3)$ & $0.0314(2)$ \\
\hline C & $0.607(2)$ & $0.831(3)$ & $0.3003(10)$ & $0.022(6)$ \\
\hline C & $-0.184(3)$ & $-0.394(2)$ & $0.1111(8)$ & $0.007(5)$ \\
\hline $\mathrm{N}$ & $-0.449(2)$ & $-0.290(2)$ & $0.2649(7)$ & $0.021(5)$ \\
\hline $\mathrm{N}$ & $-0.296(2)$ & $0.136(2)$ & $0.1840(7)$ & $0.018(5)$ \\
\hline
\end{tabular}

Estimated standard errors are given in parentheses. 


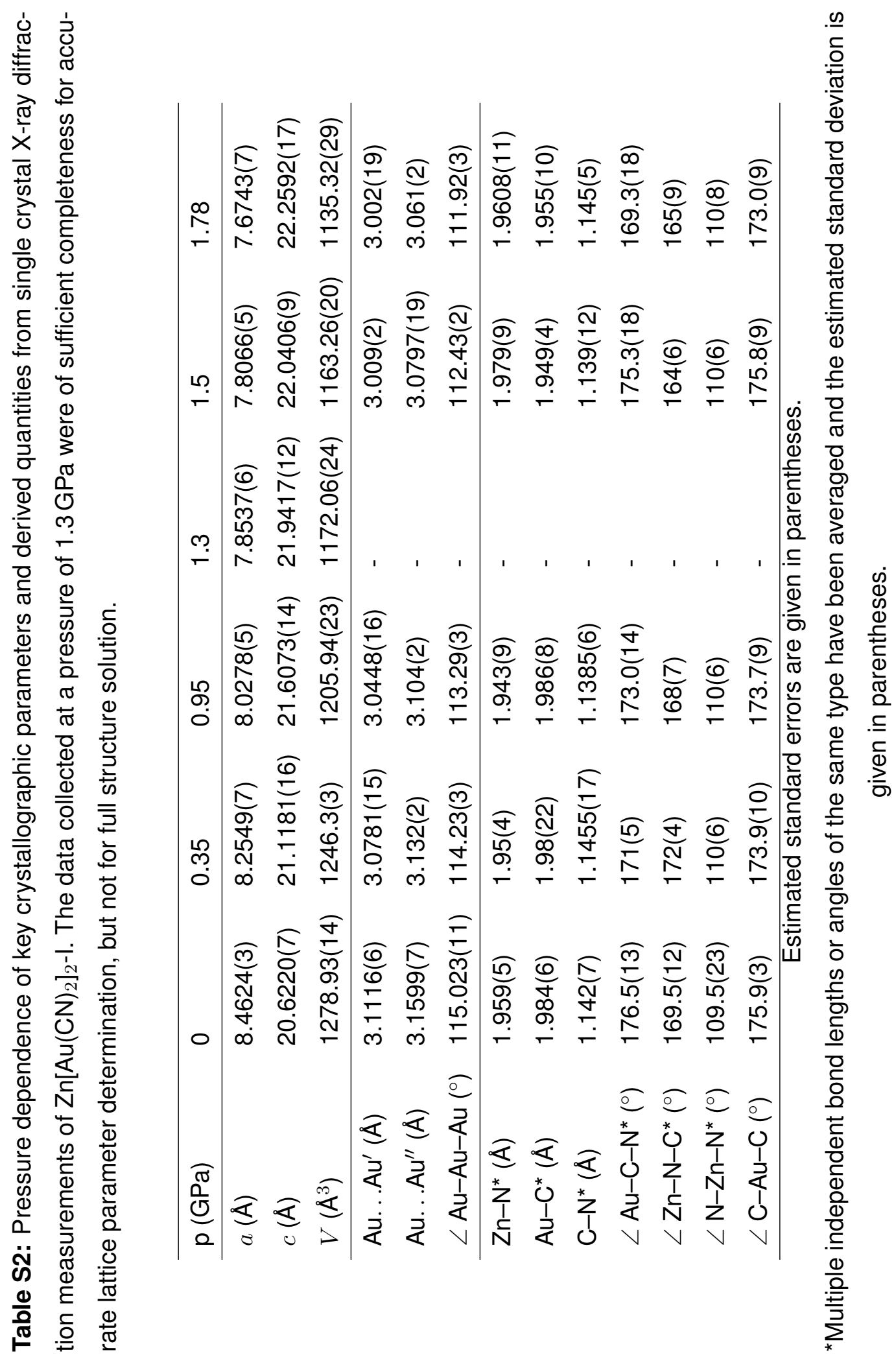




\subsection{Phase I: Variable-temperature structure refinements}

Key crystallographic details and structure refinement parameters for a single representative temperature of $100 \mathrm{~K}$ are given in Table S3. The evolution of lattice parameters and important structural features (bond lengths and bond angles) is summarised in Table S4.

Table S3: Representative single-crystal X-ray diffraction data collection and refinement details for $\mathrm{Zn}\left[\mathrm{Au}(\mathrm{CN})_{2}\right]_{2}-\mathrm{I}$ at $T=100 \mathrm{~K}$ and at ambient pressure.

\begin{tabular}{|c|c|c|c|c|}
\hline Radiation & \multicolumn{4}{|c|}{ Mo $K \alpha, \lambda=0.71073 \AA$} \\
\hline Formula & \multicolumn{4}{|l|}{$\mathrm{ZnAu}_{2} \mathrm{C}_{4} \mathrm{~N}_{4}$} \\
\hline$M\left(\mathrm{~g} \mathrm{~mol}^{-1}\right)$ & \multicolumn{4}{|l|}{563.39} \\
\hline$Z$ & \multicolumn{4}{|c|}{6} \\
\hline Crystal Size (mm) & \multicolumn{4}{|c|}{$0.106 \times 0.130 \times 0.210$} \\
\hline Crystal System & \multicolumn{4}{|l|}{ Hexagonal } \\
\hline Space Group & \multicolumn{4}{|l|}{$P 6_{2} 22$} \\
\hline$a(\AA)$ & \multicolumn{4}{|l|}{$8.3967(2)$} \\
\hline$c(\AA)$ & \multicolumn{4}{|l|}{$20.9219(7)$} \\
\hline$V\left(\AA^{3}\right)$ & \multicolumn{4}{|l|}{$1277.47(7)$} \\
\hline$w R_{\mathrm{p}}\left(F^{2}\right)$ & \multicolumn{4}{|l|}{0.062} \\
\hline Flack parameter & \multicolumn{4}{|l|}{$-0.02(3)$} \\
\hline Atom & $x$ & $y$ & $z$ & $U_{\text {eq }},\left(\AA^{2}\right)$ \\
\hline $\mathrm{Zn}$ & 0.5000 & 0.0000 & $0.62602(6)$ & 0.0085 \\
\hline $\mathrm{Au}$ & $0.31639(4)$ & $0.31687(4)$ & $0.459548(10)$ & 0.0107 \\
\hline C & $0.4020(13)$ & $0.2187(13)$ & $0.5289(4)$ & 0.0131 \\
\hline C & $0.2149(16)$ & $0.3985(13)$ & $0.3881(4)$ & 0.0175 \\
\hline $\mathrm{N}$ & $0.4455(11)$ & $0.1532(12)$ & $0.5697(3)$ & 0.0131 \\
\hline $\mathrm{N}$ & $0.7123(12)$ & $0.1491(11)$ & $0.6820(3)$ & 0.0130 \\
\hline
\end{tabular}

Estimated standard errors are given in parentheses. 


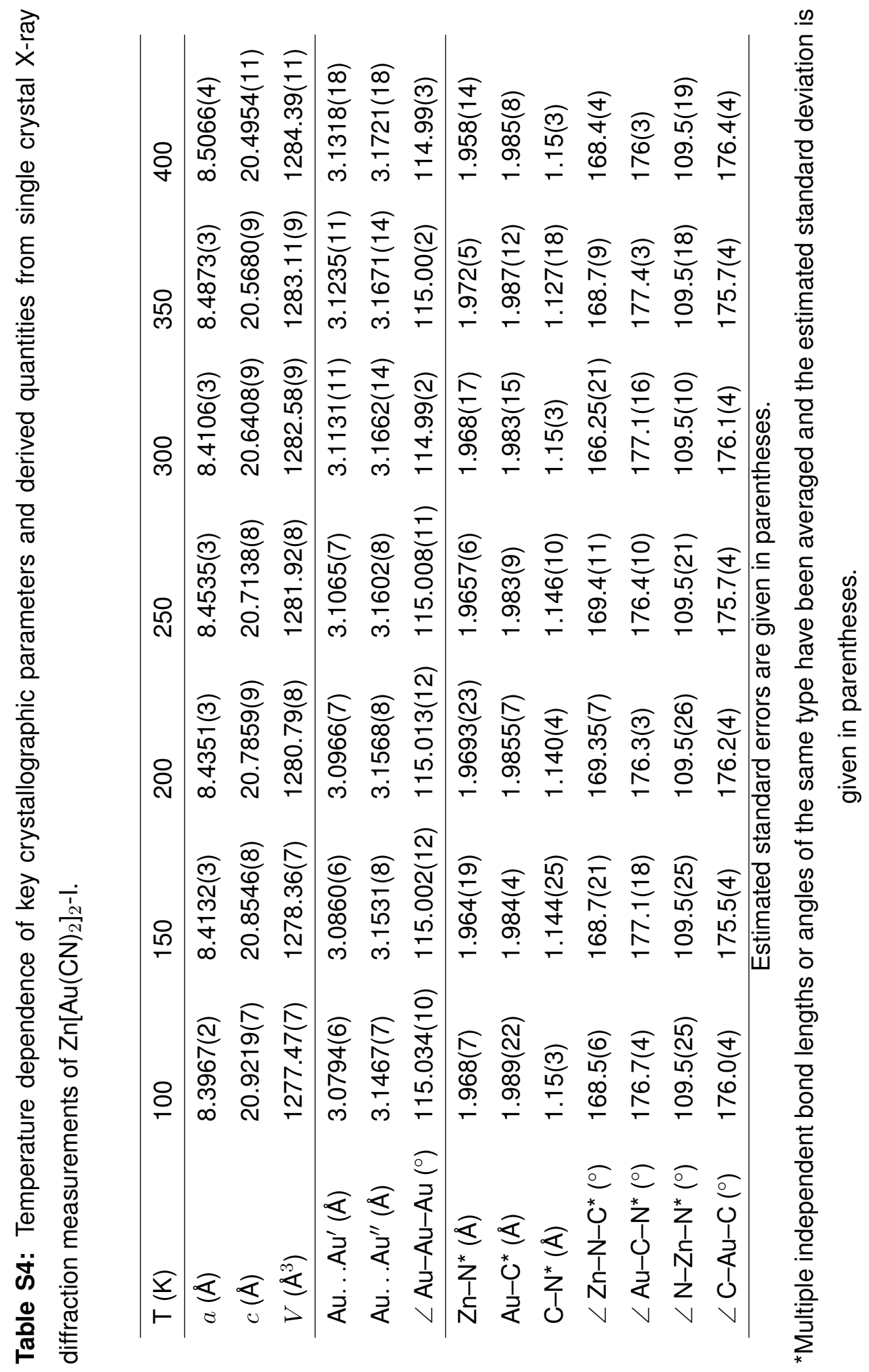




\subsection{The $1.8 \mathrm{GPa}$ phase $\mathrm{I} / \mathrm{ll}$ transition}

At a hydrostatic pressure of ca $1.8 \mathrm{GPa}$, a displacive structural transition in $\mathrm{Zn}\left[\mathrm{Au}(\mathrm{CN})_{2}\right]_{2}$ is evident in the emergence of a new set of superlattice Bragg reflections in both single-crystal and powder X-ray diffraction patterns [Fig. S3]. The positions of these additional reflections is consistent with phonon-mode softening at the L-point in reciprocal space, corresponding to a doubling the hexagonal unit cell along both the a and c crystal axes. Full crystallographic details of the new high-pressure structure are given in the following subsection; however a representation of the structure at $2.4 \mathrm{GPa}$ is given in Fig. S4. What is clear from this representation is the small magnitude of structural differences between the two crystal forms. In particular, there is no difference in network connectivity. The largest difference in relative positions is observed for the $\mathrm{Au}$ and $\mathrm{C} / \mathrm{N}$ atoms, which suggests that vibrational motion within the ambient phase is dominated by transverse displacements of these same atom types.

In Fig. S5 we show the geometry of the aurophilic helices formed by close approach of neighbouring dicyanoaurate linkers. The basic helix geometry is preserved in the high pressure phase; however there is a small shear component that reduces the effectiveness of the "spring" mechanism discussed in the main text. At increasing pressures, the helices can now distort by increasing their lateral anisotropy, which has the effect of bringing pairs of Au centres from neighbouring helices into closer proximity.

a

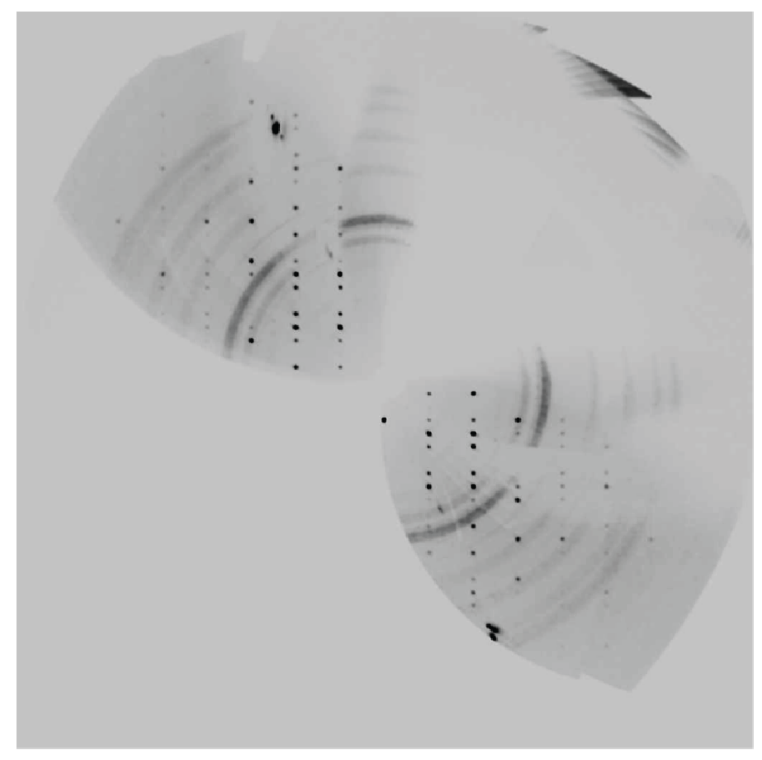

b

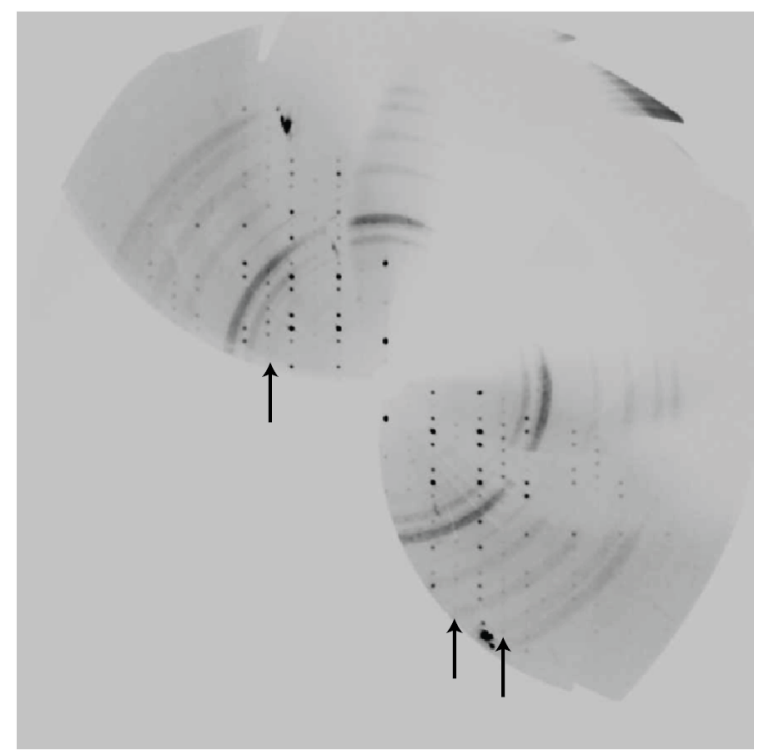

Figure S3: Reciprocal space reconstructions for the $(h 0 l)^{*}$ scattering plane in $\mathrm{Zn}\left[\mathrm{Au}(\mathrm{CN})_{2}\right]_{2}$. a Phase I (1.8 GPa, $\left.P 6_{2} 22\right)$ and $\mathbf{b}$ Phase II (3.6 GPa, $\left.P 6_{4} 22\right)$. Positions of new reflections in $\mathbf{b}$ are highlighted by arrows. 

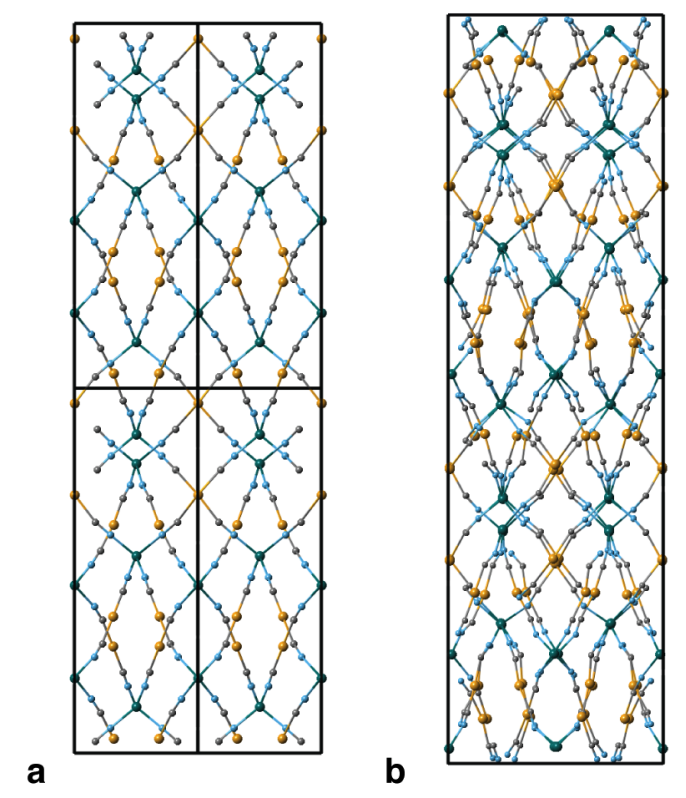

Figure S4: Relationship between $\mathbf{a}$ ambient and $\mathbf{b}$ high-pressure structures of $\mathrm{Zn}\left[\mathrm{Au}(\mathrm{CN})_{2}\right]_{2}$. The two representations are given at the same scale, such that the negative compressibility along the crystal axis (vertical) is evident.

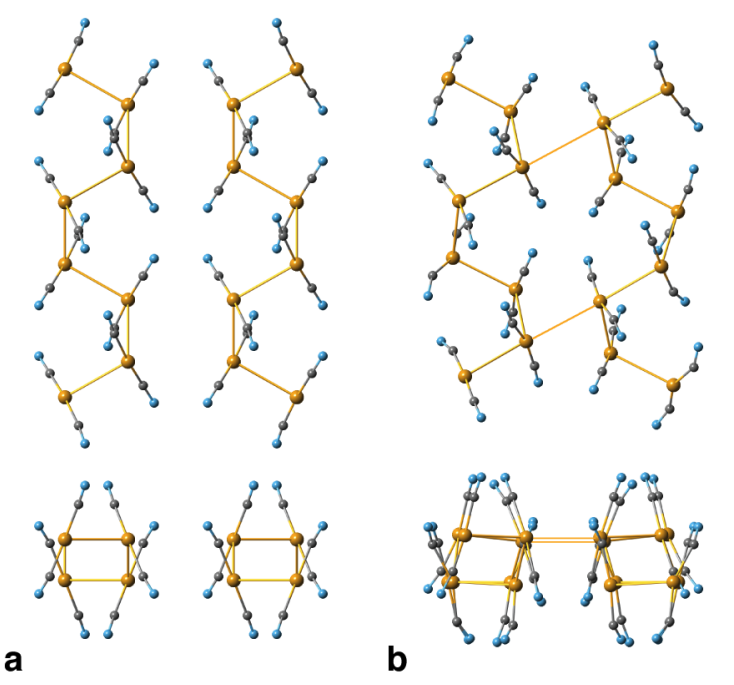

Figure S5: Aurophilic helix geometries in $\mathbf{a}$ ambient and $\mathbf{b}$ high-pressure phases of $\mathrm{Zn}\left[\mathrm{Au}(\mathrm{CN})_{2}\right]_{2}$. In the latter, the helices are slightly distorted such that moderately-short aurophilic interactions emerge between neighbouring helices $(3.5<d(\mathrm{Au}$. . Au $)<4.0 \AA)$. 


\subsection{Phase II: Variable-pressure structure refinements}

Key crystallographic details and structure refinement parameters for a single representative pressure of 3.6 GPa are given in Table S5. The evolution of lattice parameters and important structural features (bond lengths and bond angles) is summarised in Table S6.

Table S5: Representative single-crystal X-ray diffraction data collection and refinement details for $\mathrm{Zn}\left[\mathrm{Au}(\mathrm{CN})_{2}\right]_{2}-\mathrm{II}$ at $T=298 \mathrm{~K}$ and $p=3.6(10) \mathrm{GPa}$.

\begin{tabular}{|c|c|c|c|c|}
\hline Radiation & \multicolumn{4}{|c|}{ Mo $K \alpha, \lambda=0.71073 \AA$} \\
\hline Formula & \multicolumn{4}{|c|}{$\mathrm{Zn}_{8} \mathrm{Au}_{16} \mathrm{C}_{32} \mathrm{~N}_{32}$} \\
\hline$M\left(\mathrm{~g} \mathrm{~mol}^{-1}\right)$ & \multicolumn{4}{|l|}{4507.06} \\
\hline$Z$ & \multicolumn{4}{|l|}{6} \\
\hline Crystal Size (mm) & \multicolumn{4}{|c|}{$0.050 \times 0.050 \times 0.065$} \\
\hline Crystal System & \multicolumn{4}{|l|}{ Hexagonal } \\
\hline Space Group & \multicolumn{4}{|l|}{$P 6_{4} 22$} \\
\hline$a(\AA)$ & \multicolumn{4}{|l|}{$14.485(2)$} \\
\hline$c(\AA)$ & \multicolumn{4}{|l|}{$45.796(6)$} \\
\hline$V\left(\AA^{3}\right)$ & \multicolumn{4}{|l|}{$8321(2)$} \\
\hline$w R_{\mathrm{p}}\left(F^{2}\right)$ & \multicolumn{4}{|l|}{0.090} \\
\hline Flack parameter & \multicolumn{4}{|l|}{$0.01(7)$} \\
\hline Atom & $x$ & $y$ & $z$ & $U_{\text {eq }},\left(\AA^{2}\right)$ \\
\hline Au1 & $0.1130(4)$ & $0.1135(4)$ & $0.10339(12)$ & $0.0290(15)$ \\
\hline Au2 & $-0.3275(5)$ & $-0.3165(5)$ & $0.10621(12)$ & $0.0442(14)$ \\
\hline Au3 & $0.6569(5)$ & $0.1684(5)$ & $0.10811(13)$ & $0.057(2)$ \\
\hline Au4 & $0.3815(4)$ & $-0.0057(4)$ & $0.06074(11)$ & $0.0278(15)$ \\
\hline Au5 & $0.8713(5)$ & $0.3732(5)$ & $0.10271(12)$ & $0.0442(14)$ \\
\hline Au6 & $-0.3696(5)$ & $-0.4931(4)$ & $0.06550(10)$ & $0.0325(16)$ \\
\hline Aut & $0.1789(4)$ & $-0.0108(5)$ & $0.06080(9)$ & $0.0191(12)$ \\
\hline Au8 & $0.8349(4)$ & $0.5128(4)$ & $0.05883(9)$ & $0.0197(13)$ \\
\hline Zn1 & $0.4860(9)$ & $0.2394(10)$ & $0.1455(3)$ & $0.013(4)^{*}$ \\
\hline $\mathrm{Zn} 2$ & $0.5071(10)$ & $0.2555(12)$ & $0.0236(3)$ & $0.035(5)^{*}$ \\
\hline
\end{tabular}

Continued on next page 
Table S2 continued from previous page

\begin{tabular}{|c|c|c|c|c|}
\hline Zn3 & $0.0020(12)$ & $0.7544(11)$ & $0.1447(3)$ & $0.015(4)^{*}$ \\
\hline Zn4 & $0.0042(13)$ & $0.7580(11)$ & $0.0193(3)$ & $0.028(4)^{*}$ \\
\hline N1 & $0.611(2)$ & $0.254(4)$ & $0.0508(8)$ & $0.008(3)^{*}$ \\
\hline N2 & $0.411(3)$ & $0.126(4)$ & $0.1161(10)$ & $0.008(3)^{*}$ \\
\hline N3 & $0.4146(17)$ & $0.280(4)$ & $0.1749(9)$ & $0.008(3)^{*}$ \\
\hline N4 & $0.396(2)$ & $0.253(4)$ & $0.0490(7)$ & $0.008(3)^{*}$ \\
\hline N5 & $0.814(2)$ & $0.449(3)$ & $0.1597(8)$ & $0.008(3)^{*}$ \\
\hline N6 & $0.574(4)$ & $0.364(3)$ & $0.1203(9)$ & $0.008(3)^{*}$ \\
\hline N7 & $0.443(4)$ & $0.135(2)$ & $-0.0037(8)$ & $0.008(3)^{*}$ \\
\hline N8 & $-0.0381(5)$ & $0.826(3)$ & $0.1741(9)$ & $0.008(3)^{*}$ \\
\hline N9 & $-0.068(3)$ & $0.791(4)$ & $0.0509(10)$ & $0.008(3)^{*}$ \\
\hline N10 & $-0.075(4)$ & $0.670(3)$ & $0.1103(8)$ & $0.008(3)^{*}$ \\
\hline N11 & $0.113(3)$ & $0.879(3)$ & $-0.0035(7)$ & $0.008(3)^{*}$ \\
\hline N12 & $0.692(2)$ & $0.048(3)$ & $0.1582(10)$ & $0.008(3)^{*}$ \\
\hline N13 & $0.581(3)$ & $0.379(3)$ & $-0.0023(10)$ & $0.008(3)^{*}$ \\
\hline N14 & $0.929(3)$ & $0.281(4)$ & $0.0508(9)$ & $0.008(3)^{*}$ \\
\hline N15 & $0.097(4)$ & $0.838(3)$ & $0.1131(9)$ & $0.008(3)^{*}$ \\
\hline N16 & $-0.069(4)$ & $0.649(4)$ & $-0.0108(10)$ & $0.008(3)^{*}$ \\
\hline $\mathrm{C} 1$ & $0.134(5)$ & $0.928(6)$ & $-0.0246(10)$ & $0.010(4)^{*}$ \\
\hline $\mathrm{C} 2$ & $0.613(6)$ & $0.435(5)$ & $-0.0218(10)$ & $0.010(4)^{*}$ \\
\hline C3 & $0.411(6)$ & $0.073(6)$ & $0.0977(10)$ & $0.010(4)^{*}$ \\
\hline $\mathrm{C} 4$ & $0.339(7)$ & $-0.075(5)$ & $0.0225(8)$ & $0.010(4)^{*}$ \\
\hline C5 & $0.137(7)$ & $0.909(5)$ & $0.0975(9)$ & $0.010(4)^{*}$ \\
\hline C6 & $-0.070(6)$ & $0.855(6)$ & $0.1926(9)$ & $0.010(4)^{*}$ \\
\hline $\mathrm{C7}$ & $0.601(6)$ & $0.424(5)$ & $0.1017(10)$ & $0.010(4)^{*}$ \\
\hline $\mathrm{C} 8$ & $-0.063(5)$ & $-0.147(4)$ & $0.0671(9)$ & $0.010(4)^{*}$ \\
\hline $\mathrm{C9}$ & $0.370(7)$ & $0.274(8)$ & $0.0701(11)$ & $0.010(4)^{*}$ \\
\hline C10 & $-0.327(7)$ & $-0.417(7)$ & $0.0282(10)$ & $0.010(4)^{*}$ \\
\hline C11 & $0.630(7)$ & $0.223(7)$ & $0.0716(11)$ & $0.010(4)^{*}$ \\
\hline
\end{tabular}


Table S2 continued from previous page

\begin{tabular}{lllll}
\hline C12 & $0.358(4)$ & $0.276(4)$ & $0.1928(10)$ & $0.010(4)^{*}$ \\
C13 & $0.924(6)$ & $0.337(4)$ & $0.0674(10)$ & $0.010(4)^{*}$ \\
C14 & $-0.121(6)$ & $0.602(5)$ & $0.0944(10)$ & $0.010(4)^{*}$ \\
C15 & $0.669(8)$ & $0.094(6)$ & $0.1423(11)$ & $0.010(4)^{*}$ \\
C16 & $0.834(7)$ & $0.416(7)$ & $0.1396(11)$ & $0.010(4)^{*}$ \\
\hline
\end{tabular}

Estimated standard deviations are given in parentheses.

${ }^{*} U_{\text {eq }}$ have been constrained to be equal in atoms of the same type. 
Table S6: Pressure dependence of key crystallographic parameters and derived quantities from single crystal X-ray diffraction measurements of $\mathrm{Zn}\left[\mathrm{Au}(\mathrm{CN})_{2}\right]_{2}$-II. The data collected at pressures of 2.2 and $3.1 \mathrm{GPa}$ were of sufficient completeness for accurate lattice parameter determination, but not for full structure solution.

\begin{tabular}{|c|c|c|c|c|}
\hline$p(\mathrm{GPa})$ & 2.2 & 2.4 & 3.1 & 3.6 \\
\hline$a(\AA)$ & $15.054(3)$ & $14.936(3)$ & $14.594(4)$ & $14.485(2)$ \\
\hline$c(\AA)$ & $45.025(5)$ & $45.092(7)$ & $45.609(7)$ & $45.796(6)$ \\
\hline$V\left(\AA^{3}\right)$ & $8837(5)$ & $8712(5)$ & $8413(6)$ & $8321(3)$ \\
\hline$A u \ldots A u^{\prime *}(\AA)$ & - & $3.01(4)$ & - & $2.98(6)$ \\
\hline$A u . . . A u^{\prime \prime} *(\AA)$ & - & $3.05(8)$ & - & $3.05(5)$ \\
\hline Additional Au. . .Au (Å) & - & - & - & $3.32(5)$ \\
\hline$\angle A u-A u-A u^{*}\left({ }^{\circ}\right)$ & - & $111(8)$ & - & $110(10)$ \\
\hline $\mathrm{Zn}-\mathrm{N}^{*}(\AA)$ & - & $1.970(8)$ & - & $1.965(9)$ \\
\hline$A u-C^{*}(\AA)$ & - & $1.960(7)$ & - & $1.966(9)$ \\
\hline$C-N^{*}(\AA)$ & - & $1.146(19)$ & - & $1.14(4)$ \\
\hline$\angle \mathrm{Au}-\mathrm{C}-\mathrm{N}^{*}\left({ }^{\circ}\right)$ & - & $163(8)$ & - & $165(8)$ \\
\hline$\angle \mathrm{Zn}-\mathrm{N}-\mathrm{C}^{*}\left({ }^{\circ}\right)$ & - & $164(8)$ & - & $160(8)$ \\
\hline$\angle \mathrm{N}-\mathrm{Zn}-\mathrm{N}^{*}\left({ }^{\circ}\right)$ & - & $110(12)$ & - & $110(25)$ \\
\hline$\angle \mathrm{C}-\mathrm{Au}-\mathrm{C}^{*}\left(^{\circ}\right)$ & - & $169(6)$ & - & $172.5(18)$ \\
\hline
\end{tabular}

*Multiple independent bond lengths or angles of the same type have been averaged and the estimated standard deviation is given in parentheses. 


\section{Crystallographic Analysis of Powder X-ray Diffraction Data}

The powder X-ray diffraction data were of sufficient quality only to refine lattice parameters and peak shape profile variables, while making use of (fixed) atomic coordinates as determined using our single-crystal X-ray diffraction measurements. Consequently the fits obtained are not of the same quality as Pawley refinements, but are more meaningful in the sense that a physically-sensible structural model is used to determine intensities. As in previous studies of flexible materials with highly anisotropic mechanical properties, we found evidence of strong $(h k l)$ dependence in the peak asymmetries. ${ }^{S 16}$ This occurs because individual crystallites expand and contract in different directions as a function of hydrostatic pressure, and this results in an inhomogeneous distribution of inter-particle stresses throughout the polycrystalline sample. The presence of both NLC and PLC axes means that there are some crystal axes along which the compressibility is close to zero; for reflections that correspond to crystal directions parallel to these axes, the stresses are very small (hence the reflections show small peak asymmetries). For reflections corresponding to crystal directions parallel to the strongest NLC and PLC axes, the stresses are very large (hence these reflections show large peak asymmetries). Within the truly-hydrostatic fluorinert regime $(p<2 \mathrm{GPa})$ the contrast between sharp and broadened peaks is sufficiently large that completely satisfactory fits to the very sharpest intense peak (the (104) reflection by virtue of the relation $K_{a}^{2} / K_{c}^{2} \simeq 4 a / c$ ) are not in fact feasible.

Lattice parameters were derived using the Rietveld method ${ }^{517}$ as implemented within the TOPAS suite of programs, ${ }^{S 18}$ which is suited for its ability to model unusual peak shape functions. Peak shapes were fitted initially using a normal pseudo-voigt function. In order to account for the anisotropic strain broadening it was necessary (i) to add to this function an isotropic broadening term (of Lorentzian shape), and (ii) to convolute the resultant peak with an $h k l$ dependent exponential function in order to model the observed asymmetry. This asymmetry was evident in some reflections having peak shapes which trailed to high $d$-spacing and others with peak shapes trailing to low $d$-spacing. In our analysis we found that a suitable fourth-order spherical harmonic function reproduced this asymmetry well, with both the isotropic strain term and anisotropic broadening contribution varying smoothly towards zero at room temperature.

The corresponding fits to data are shown in Figs. S6 and S7 for the ambient and highpressure phases, respectively. The lattice parameters derived from these fits are listed in Tables S7 and S8.

Table S7: Pressure dependence of the lattice parameters of $\mathrm{Zn}\left[\mathrm{Au}(\mathrm{CN})_{2}\right]_{2}-\mathrm{I}$ as determined using synchrotron powder X-ray diffraction measurements.

\begin{tabular}{llll}
\hline$p(\mathrm{GPa})$ & $a(\AA)$ & $c(\AA)$ & $V\left(\AA^{3}\right)$ \\
\hline $0.79(10)$ & $8.0921(22)$ & $21.438(7)$ & $1215.7(11)$ \\
$1.02(10)$ & $8.0051(27)$ & $21.612(9)$ & $1199.4(13)$ \\
$1.17(10)$ & $7.949(5)$ & $21.700(14)$ & $1187.6(22)$ \\
$1.36(10)$ & $7.793(7)$ & $22.048(17)$ & $1160(3)$ \\
$1.56(10)$ & $7.7208(28)$ & $22.147(13)$ & $1143.3(15)$ \\
\hline
\end{tabular}




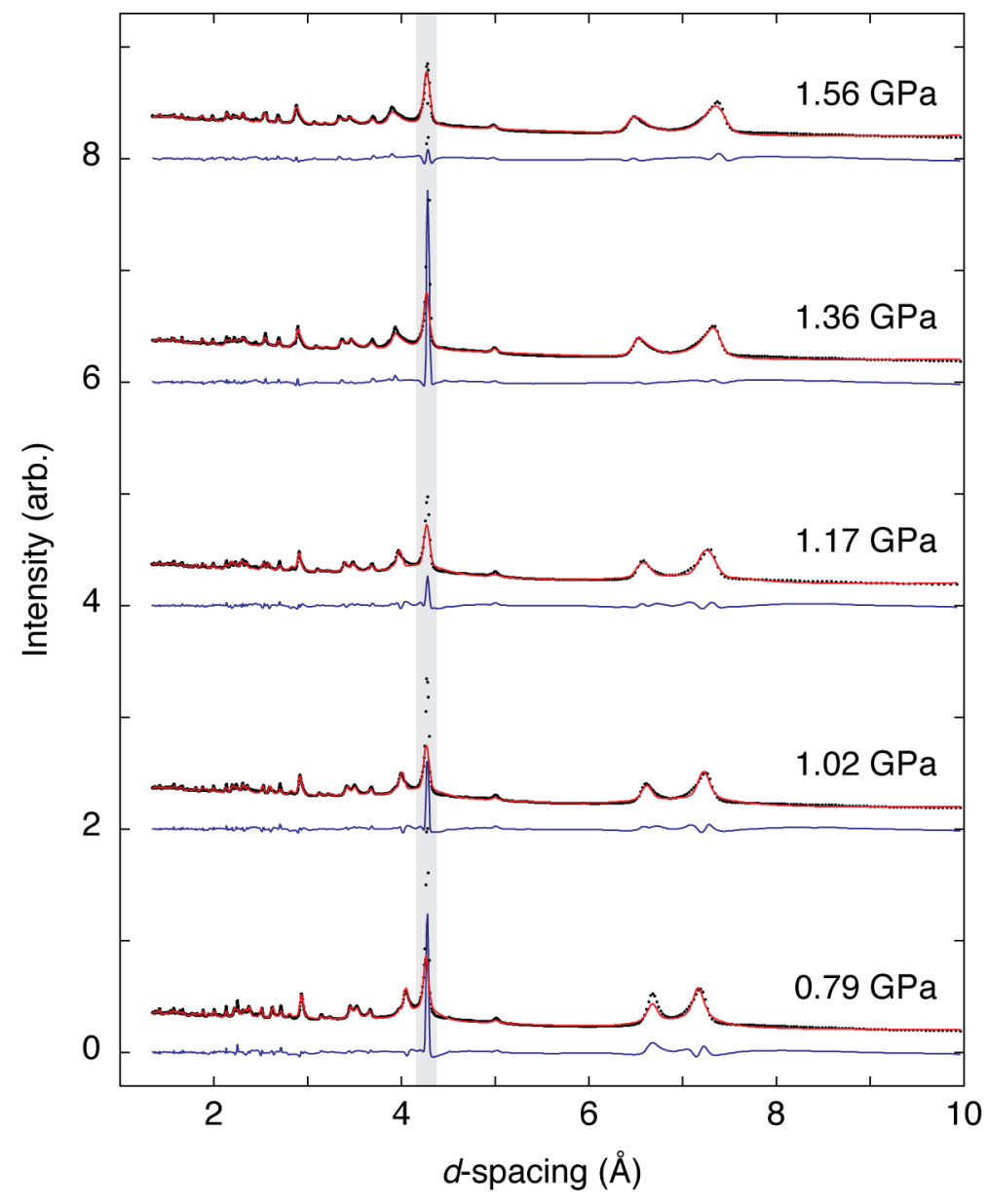

Figure S6: Rietveld fits (red lines) to synchrotron powder X-ray diffraction data (filled black circles) collected for $\mathrm{Zn}\left[\mathrm{Au}(\mathrm{CN})_{2}\right]_{2}-$ I. The difference (data-fit) is shown in blue under each data set. Successive data sets, fits and difference functions are shifted vertically by two units. The sharpest intense peak (the (104) reflection), for which quantitative fits are not feasible, occurs within the shaded region. 


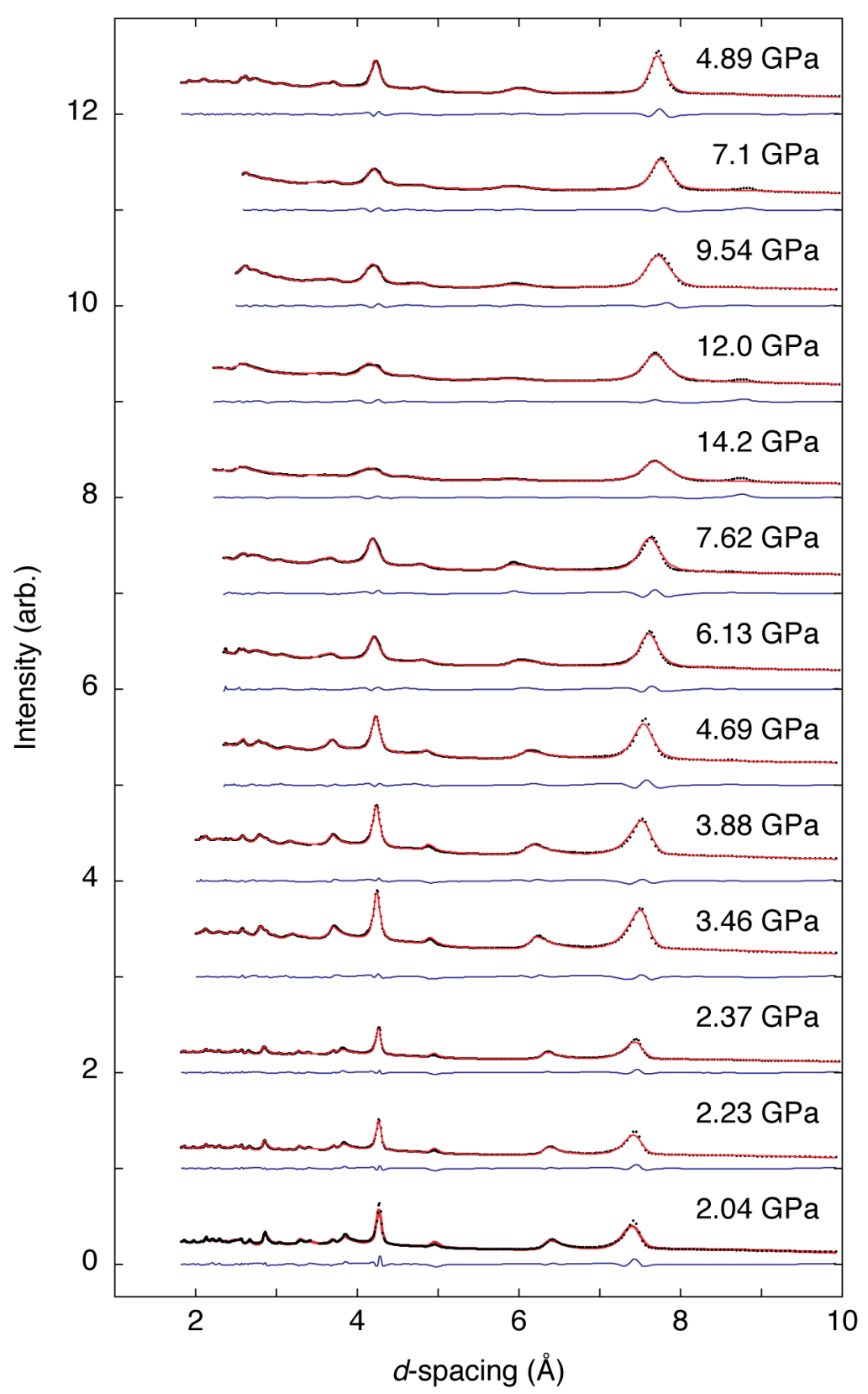

Figure S7: Rietveld fits to synchrotron powder X-ray diffraction data collected for the highpressure phase $\mathrm{Zn}\left[\mathrm{Au}(\mathrm{CN})_{2}\right]_{2}-$ II. The difference (data-fit) is shown in blue under each data set. Successive data sets, fits and difference functions are shifted vertically by one unit. 
Table S8: Pressure dependence of the lattice parameters of $\mathrm{Zn}\left[\mathrm{Au}(\mathrm{CN})_{2}\right]_{2}-\mathrm{II}$ as determined using synchrotron powder X-ray diffraction measurements.

\begin{tabular}{llll}
\hline$p(\mathrm{GPa})$ & $a(\AA)$ & $c(\AA)$ & $V\left(\AA^{3}\right)$ \\
\hline $2.04(10)$ & $15.227(8)$ & $44.64(4)$ & $8963(18)$ \\
$2.23(10)$ & $15.165(8)$ & $44.75(4)$ & $8913(16)$ \\
$2.37(10)$ & $15.101(7)$ & $44.85(3)$ & $8857(14)$ \\
$3.46(10)$ & $14.71(3)$ & $45.27(7)$ & $8481(50)$ \\
$3.88(10)$ & $14.570(10)$ & $45.43(5)$ & $8353(22)$ \\
$4.69(10)$ & $14.452(11)$ & $45.66(5)$ & $8260(23)$ \\
$6.13(10)$ & $14.117(19)$ & $45.67(6)$ & $7880(30)$ \\
$7.62(10)$ & $14.005(18)$ & $46.19(7)$ & $7850(30)$ \\
$10.66(10)$ & $13.73(9)$ & $46.2(4)$ & $7530(160)$ \\
$14.22(10)$ & $13.342(23)$ & $45.93(13)$ & $7080(40)$ \\
\hline
\end{tabular}




\section{Compressibilities and Equations of State}

\subsection{Approach}

The compressibilities of $\mathrm{Zn}\left[\mathrm{Au}(\mathrm{CN})_{2}\right]_{2}$ in both its low- and high-pressure phases were determined by fitting empirical functions to the experimental lattice parameter data and hence calculating $K_{\ell}(p)$. The reporting of NLC is often done on the basis of fitting $\Delta \ell(p) / \ell_{0}$ to a polynomial function $A p+B p^{2}+C p^{3} \ldots$ and then quoting the value of $A$ as $K_{\ell_{0}}$; however this approach tends to overestimate $K_{\ell_{0}}$ severely in cases where NLC diverges at low pressures. We have chosen instead to fit $\Delta \ell(p)$ to the simple empirical expression: ${ }^{\mathrm{S} 19}$

$$
\ell=\ell_{0}+\lambda\left(p-p_{c}\right)^{\nu} .
$$

For the high-pressure phase, there is some evidence that the negative value of $K_{c}$ does not persist for arbitrary pressure; rather it seems that there is a reversion to positive compressibilities for pressures above ca $10 \mathrm{GPa}$. The expression given in Eq. 1 does not allow for a change of sign in compressibility. Consequently, for this phase the change-of-basis approach used in similar circumstances elsewhere ${ }^{\$ 20}$ was implemented. Here the corresponding variables are $\mathrm{Zn}$...Zn separation $k$ and Zn-Zn-Zn pseudo-tetrahedral angle $2 \theta$ :

$$
\begin{aligned}
k & =\sqrt{\frac{3}{4} a^{2}+\frac{1}{9} c^{2}} \\
\theta & =\cos ^{-1}\left(\frac{c}{3 k}\right) .
\end{aligned}
$$

Fitting is then to the experimental functions $k(p)$ and $\theta(p)$ according to Eq. (1), with lattice compressibilities obtained by parameter inversion:

$$
\begin{aligned}
K_{a} & =\frac{2 k}{\sqrt{3} a}\left(K_{k} \sin \theta+\theta K_{\theta} \cos \theta\right) \\
K_{c} & =\frac{3 k}{c}\left(K_{k} \cos \theta-\theta K_{\theta} \sin \theta\right) .
\end{aligned}
$$

\subsection{Experimental compressibility fitting}

Mean linear compressibilities calculated using this approach are listed in Table S9; the full pressure-dependencies of the compressibilities for phases I and II are given in Tables S10 and S11, respectively.

Table S9: Median axial compressibilities of $\mathrm{Zn}\left[\mathrm{Au}(\mathrm{CN})_{2}\right]_{2}$.

\begin{tabular}{lll}
\hline & $K_{a}\left(\mathrm{TPa}^{-1}\right)$ & $K_{c}\left(\mathrm{TPa}^{-1}\right)$ \\
\hline $\mathrm{Zn}\left[\mathrm{Au}(\mathrm{CN})_{2}\right]_{2}-\mathrm{I}$ & $52(6)$ & $-42(5)$ \\
$\mathrm{Zn}\left[\mathrm{Au}(\mathrm{CN})_{2}\right]_{2}-\mathrm{II}$ & $16(5)$ & $-6(3)$ \\
\hline
\end{tabular}


Table S10: Axial compressibilities of $\mathrm{Zn}\left[\mathrm{Au}(\mathrm{CN})_{2}\right]_{2}$-I determined via empirical fits to experimental lattice parameter data.

\begin{tabular}{lll}
\hline$p(\mathrm{GPa})$ & $K_{a}\left(\mathrm{TPa}^{-1}\right)$ & $K_{c}\left(\mathrm{TPa}^{-1}\right)$ \\
\hline 0.35 & $55(16)$ & $-48(14)$ \\
0.79 & $53(5)$ & $-44(4)$ \\
0.95 & $53(4)$ & $-43.6(29)$ \\
1.02 & $53(3)$ & $-43.3(29)$ \\
1.17 & $53(4)$ & $-43(3)$ \\
1.3 & $53(5)$ & $-42(4)$ \\
1.36 & $52(6)$ & $-42(5)$ \\
1.47 & $52(6)$ & $-42(5)$ \\
1.5 & $52(7)$ & $-42(5)$ \\
1.56 & $52(7)$ & $-42(6)$ \\
1.78 & $52(9)$ & $-41(7)$ \\
\hline
\end{tabular}

Estimated standard errors are given in parentheses. 
Table S11: Axial compressibilities of $\mathrm{Zn}\left[\mathrm{Au}(\mathrm{CN})_{2}\right]_{2}-$ II determined via empirical fits to experimental lattice parameter data.

\begin{tabular}{lll}
\hline$p(\mathrm{GPa})$ & $K_{a}\left(\mathrm{TPa}^{-1}\right)$ & $K_{c}\left(\mathrm{TPa}^{-1}\right)$ \\
\hline 2.04 & $75(5)$ & $-51(3)$ \\
2.2 & $51(5)$ & $-31(3)$ \\
2.2335 & $48(5)$ & $-30(3)$ \\
2.368 & $39(5)$ & $-23(3)$ \\
2.4 & $38(5)$ & $-21(3)$ \\
3.1 & $22(5)$ & $-10(3)$ \\
3.4575 & $18(5)$ & $-8(3)$ \\
3.6 & $18(5)$ & $-7(3)$ \\
3.8755 & $16(5)$ & $-6(3)$ \\
4.6905 & $13(5)$ & $-4(3)$ \\
4.89 & $13(5)$ & $-3(3)$ \\
6.128 & $10(5)$ & $-2(3)$ \\
7.1 & $9(5)$ & $-1(3)$ \\
7.6165 & $8(5)$ & $-1(3)$ \\
9.54 & $7(5)$ & $0(3)$ \\
10.66 & $6(5)$ & $0(3)$ \\
12 & $6(5)$ & $0(3)$ \\
14.223 & $5(5)$ & $0(3)$ \\
\hline \hline & &
\end{tabular}




\subsection{Equation of state fitting}

The Pressure dependence of the crystallographic unit cell volumes of both phases I and II were fitted to Birch-Murnaghan equations of state ${ }^{\mathrm{S} 21}$

$$
p=\frac{3 B_{0}}{2}\left[\left(\frac{V_{0}}{V}\right)^{\frac{7}{3}}-\left(\frac{V_{0}}{V}\right)^{\frac{5}{3}}\right]\left[1+\frac{3}{4}\left(B^{\prime}-4\right)\left(\left(\frac{V}{V_{0}}\right)^{-\frac{2}{3}}-1\right)\right],
$$

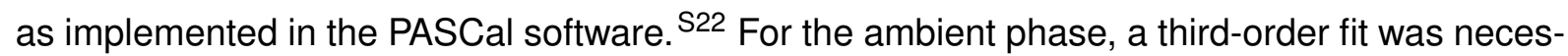
sary in order to capture the unusual pressure-induced softening described in the main text. For the high-pressure phase $\mathrm{Zn}\left[\mathrm{Au}(\mathrm{CN})_{2}\right]_{2}-\mathrm{II}$ a reasonable fit was obtained using a second-order $\left(B^{\prime} \equiv 4\right)$ equation of state. Extracted zero-pressure bulk moduli $\left(B_{0}\right)$ and the pressure derivative of the bulk modulus $B^{\prime}$ are given in Table S12; the corresponding fits to our experimental $V(p)$ data are given in Fig. S8.

Table S12: Zero-pressure bulk modulus $B_{0}$ and the pressure derivative of the bulk modulus $B^{\prime}$ determined for $\mathrm{Zn}\left[\mathrm{Au}(\mathrm{CN})_{2}\right]_{2}$ via Birch-Murnaghan equation of state fits to our experimental $V(p)$ data.

\begin{tabular}{lll}
\hline & $B_{0}(\mathrm{GPa})$ & $B^{\prime}$ \\
\hline $\mathrm{Zn}\left[\mathrm{Au}(\mathrm{CN})_{2}\right]_{2}-\mathrm{I}$ & $16.7(16)$ & $-1.7(11)$ \\
$\mathrm{Zn}\left[\mathrm{Au}(\mathrm{CN})_{2}\right]_{2}-\mathrm{II}$ & $27(3)$ & 4 \\
\hline
\end{tabular}




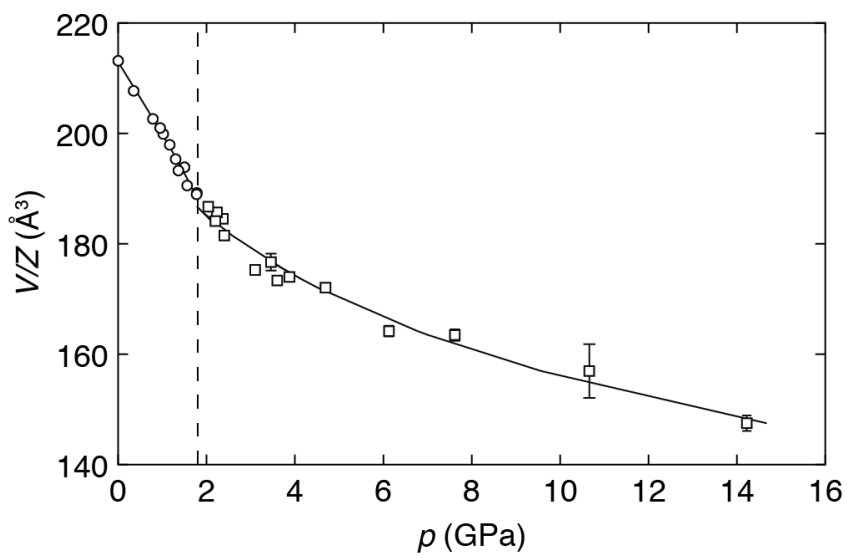

Figure S8: Variation of molar volume $V / Z$ of $\mathrm{Zn}\left[\mathrm{Au}(\mathrm{CN})_{2}\right]_{2}-\mathrm{I}$ and $\mathrm{Zn}\left[\mathrm{Au}(\mathrm{CN})_{2}\right]_{2}-\mathrm{Il}$ between 0 and $14 \mathrm{GPa}$, as determined by powder and single crystal X-ray diffraction measurements. A third-order Birch-Murnaghan fit is shown to the data for $\mathrm{Zn}\left[\mathrm{Au}(\mathrm{CN})_{2}\right]_{2}-\mathrm{I}$ and a second order fit is shown for the high-pressure phase $\mathrm{Zn}\left[\mathrm{Au}(\mathrm{CN})_{2}\right]_{2}-\mathrm{II}$. 


\section{Geometric Considerations of NLC in Uniaxial Networks}

The central concept we develop here is that for many framework systems the entire set of lattice compressibilities (including the bulk modulus) are a function simply of (i) a single linear compressibility value, and (ii) the aspect ratio $\rho=c / a$. We illustrate this point with two simple framework geometries that give rise to NLC: namely the "wine-rack" and "honeycomb" networks. We then proceed to derive a general expression for NLC in the $\beta$-quartz topology of $\mathrm{Zn}\left[\mathrm{Au}(\mathrm{CN})_{2}\right]_{2}$. We note that our approach here follows closely the results of supplementary Refs. S23 and S24.

Consider first the wine-rack network illustrated in Fig. S9(a). The conventional crystallographic structural description is given by the pair of lattice parameters $a, c$; however it is possible to describe the geometry of this structure with the two alternate parameters $k$ (the strut length) and $\theta$ (the folding angle). The two pairs of parameters are related by the expressions:

$$
\begin{aligned}
& a=2 k \cos \theta \\
& c=2 k \sin \theta .
\end{aligned}
$$

In the limit of small distortions to the framework strut lengths, the only parameter that varies under changes in pressure will be $\theta ;$ i.e., $\mathrm{d} k / \mathrm{d} p=0$. Hence the derivatives of the lattice parameters $a$ and $c$ with respect to pressure are

$$
\begin{aligned}
& \frac{\mathrm{d} a}{\mathrm{~d} p}=-2 k \sin \theta \frac{\mathrm{d} \theta}{\mathrm{d} p} \\
& \frac{\mathrm{d} c}{\mathrm{~d} p}=2 k \cos \theta \frac{\mathrm{d} \theta}{\mathrm{d} p} .
\end{aligned}
$$

Substituting $\rho=c / a$ and evaluating for compressibilities, it follows that

$$
K_{c}=-\frac{1}{\rho^{2}} K_{a}
$$

and hence the value of $K_{c}$ is determined uniquely by $K_{a}$ and $\rho$. The intrinsic NLC effect also follows immediately: a positive value of $K_{a}$ implies NLC along the $c$-axis, with the magnitude of NLC proportional to the magnitude of $K_{a}$ for fixed $\rho$.

Extending this analysis to the two-dimensional honeycomb geometry of Fig. S9(b), one finds a similar relationship amongst the variables $a, c, k, \theta$ :

$$
\begin{aligned}
a & =2 k \cos \theta \\
c & =2 k[1+\sin \theta],
\end{aligned}
$$

giving

$$
\begin{aligned}
& \frac{\mathrm{d} a}{\mathrm{~d} p}=-2 k \sin \theta \frac{\mathrm{d} \theta}{\mathrm{d} p} \\
& \frac{\mathrm{d} c}{\mathrm{~d} p}=2 k \cos \theta \frac{\mathrm{d} \theta}{\mathrm{d} p}
\end{aligned}
$$

as above. By defining

$$
\rho=\frac{c}{a}=\frac{1+\sin \theta}{\cos \theta}
$$




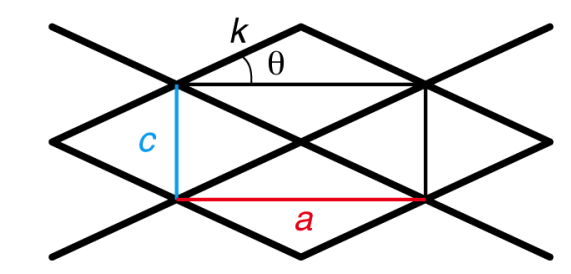

a

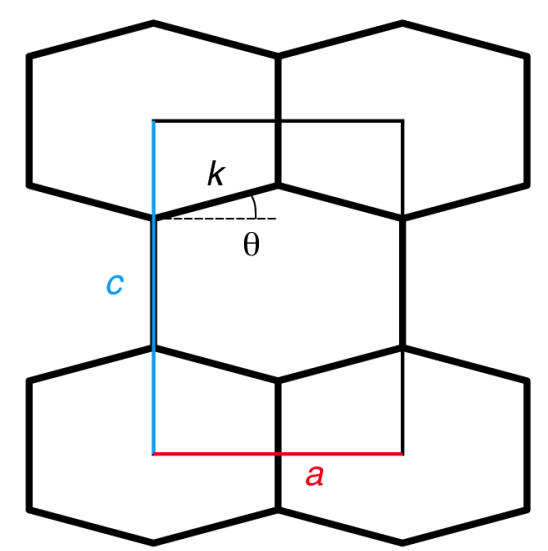

b

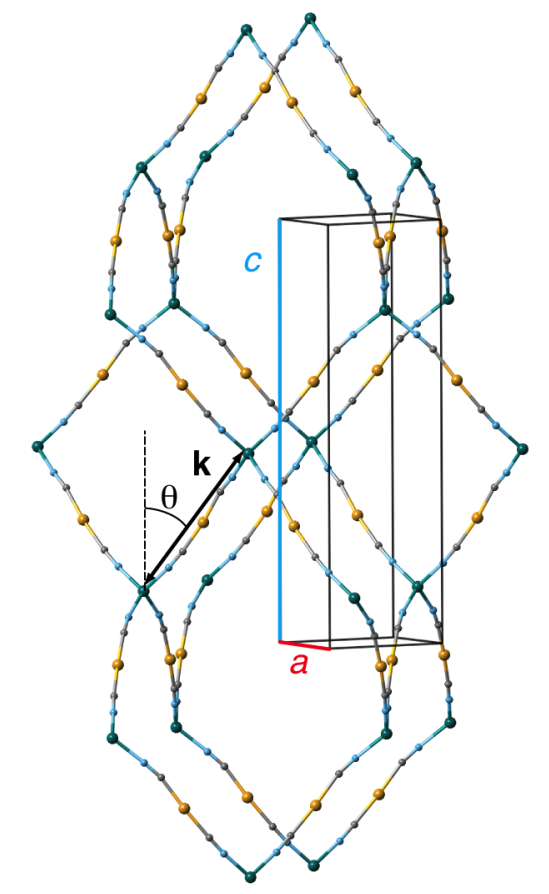

c

Figure S9: Uniaxial network geometries discussed in the text: (a) wine-rack, (b) honeycomb, and (c) $\beta$-quartz.

one obtains

$$
\frac{\mathrm{d} \theta}{\mathrm{d} p}=\frac{2 \rho}{\rho^{2}-1} K_{a},
$$

and hence the result

$$
K_{c}=-\frac{2}{\rho^{2}-1} K_{a} .
$$

So, again, one finds that a positive value of $K_{a}$ not only implies NLC along the the $c$-axis but also the magnitudes of the two effects are directly proportional for a given aspect ratio $\rho .{ }^{1}$

Turning finally to the $\beta$-quartz topology of $\mathrm{Zn}\left[\mathrm{Au}(\mathrm{CN})_{2}\right]_{2}$, the pair of lattice parameters $a, c$ can be recast in terms of a network vector $\mathrm{k}$ [Fig. S9(c)]:

$$
\mathbf{k}=\frac{1}{2} \mathbf{a}+\mathbf{b}+\frac{1}{3} \mathbf{c} .
$$

${ }^{1}$ We note here that the "honeycomb" and "inverse honeycomb" nets are distinguished by positive and negative values of $\theta$, respectively. Within the constraint $\theta>0$ one has $\rho=c / a>1$ and hence $K_{c}$ and $K_{a}$ have opposite signs. By contrast, the inverse honeycomb net gives rise to $K_{a}$ and $K_{c}$ values of the same sign (since the prefactor $-2 /\left(\rho^{2}-1\right)$ is positive in that instance). 
The magnitude of this vector

$$
k=\sqrt{\frac{3}{4} a^{2}+\frac{1}{9} c^{2}}
$$

and the angle $\theta$ formed between $\mathbf{k}$ and the unit cell axis $\mathbf{c}$ are sufficient to describe $a$ and $c$ uniquely:

$$
\begin{aligned}
c & =3 k \cos \theta \\
a & =\frac{2}{\sqrt{3}} k \sin \theta .
\end{aligned}
$$

Following an analysis similar to that above, one obtains the relationship between linear coefficients of thermal expansion

$$
K_{c}=-\frac{27}{4 \rho^{2}} K_{a},
$$

where $\rho=c / a$. Again the magnitude of NLC along $\mathbf{c}$ is directly proportional to the extent of PLC along a.

In order to demonstrate that the above analysis is entirely consistent with our experimental data, we make use of the following relationship between the bulk modulus $B$ and the linear compressibilities in a three-dimensional uniaxial solid:

$$
B=\frac{1}{2 K_{a}+K_{c}} .
$$

Because $K_{c}$ and $K_{a}$ are related via $\rho$, this means that the experimental values of $B(=16.7 \mathrm{GPa})$ and $\rho(\simeq 2.8)$ can be used to predict an expected value for the magnitude of $\mathrm{NLC}$ in $\mathrm{Zn}\left[\mathrm{Au}(\mathrm{CN})_{2}\right]_{2}$ :

$$
K_{c}=\frac{1}{16.7 \mathrm{GPa}}\left[1-\frac{8 \rho^{2}}{27}\right]^{-1}=-45 \mathrm{TPa}^{-1} .
$$

The excellent comparison between measured values of $K_{c}$ and the values anticipated by this expression-as shown in Fig. S10-is direct evidence that the compressibility mechanism activated in $\mathrm{Zn}\left[\mathrm{Au}(\mathrm{CN})_{2}\right]_{2}$ involves network hingeing, but very little network deformation. In other words, the approximation $\mathrm{d} k / \mathrm{d} p=0$ holds. 
Figure S10: Comparison between experimental values of the NLC coefficient $K_{c}$ and those calculated from Eq. (25). (Red line) compressibility in the $c$ direction at arbitrary values of $\rho$ required by the experimental bulk modulus $B=16.7 \mathrm{GPa}$; (blue circles) experimental values.

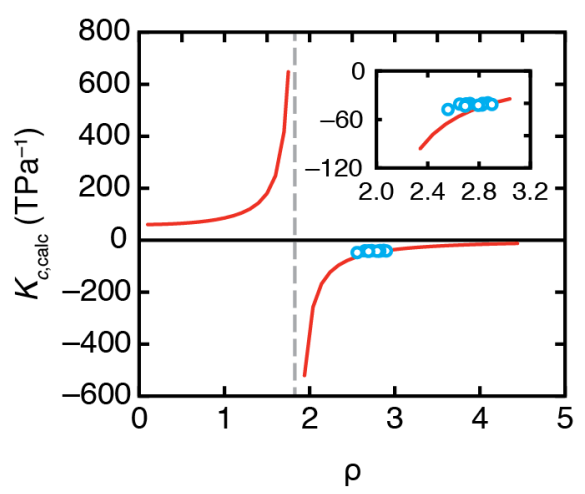




\section{Raman Spectroscopic Analysis}

The Pressure dependence of Raman-active vibrational frequencies is shown in Fig. S11. At pressures below the I/II phase transition there are a number of modes present that possess negative Grüneisen parameters; i.e., their frequencies decrease with increasing pressure. Perhaps the most important of these is the very lowest-energy mode measurable experimentally (shown as green triangles in Fig. S11). The existence of such modes is not unusual for materials that show negative thermal expansion behaviour (negative values of some mode Grüneisen parameters being one pre-requisite). However, this behaviour does mean that on compression there is a high probability of structural phase transitions as the relevant mode(s) condense(s). The phase transition we observe at $1.8 \mathrm{GPa}$ cannot be directly associated with the softening of one of the modes we observe in the Raman spectrum, since the transition occurs via condensation at the L-point on the Brillouin zone boundary. Consequently the existence of soft modes both at the zone centre (as we observe here) and at the zone boundary (implied by the phase transition) suggests the presence of at least one soft branch of the phonon dispersion.

Given the large number of modes expected from group theory, the spectra themselves are much too complex to assign uniquely. What we do know from the structural distortions associated with the high-pressure phase transition is that the soft mode involves strong coupling between the Au. . Au vibrations and tilting of the $\left[\mathrm{ZnN}_{4}\right]$ coordination polyhedra.

At pressures above $1.8 \mathrm{GPa}$ all mode frequencies adopt positive $\mathrm{d} \omega / \mathrm{d} p$ values-a result that is consistent with the experimentally-observed stiffening of the bulk modulus. Consistent with the symmetry-lowering nature of the phase transition, a number of additional peaks are discernible in the Raman spectrum, although at higher pressures significant peak broadening makes resolution of individual peaks increasingly difficult. 


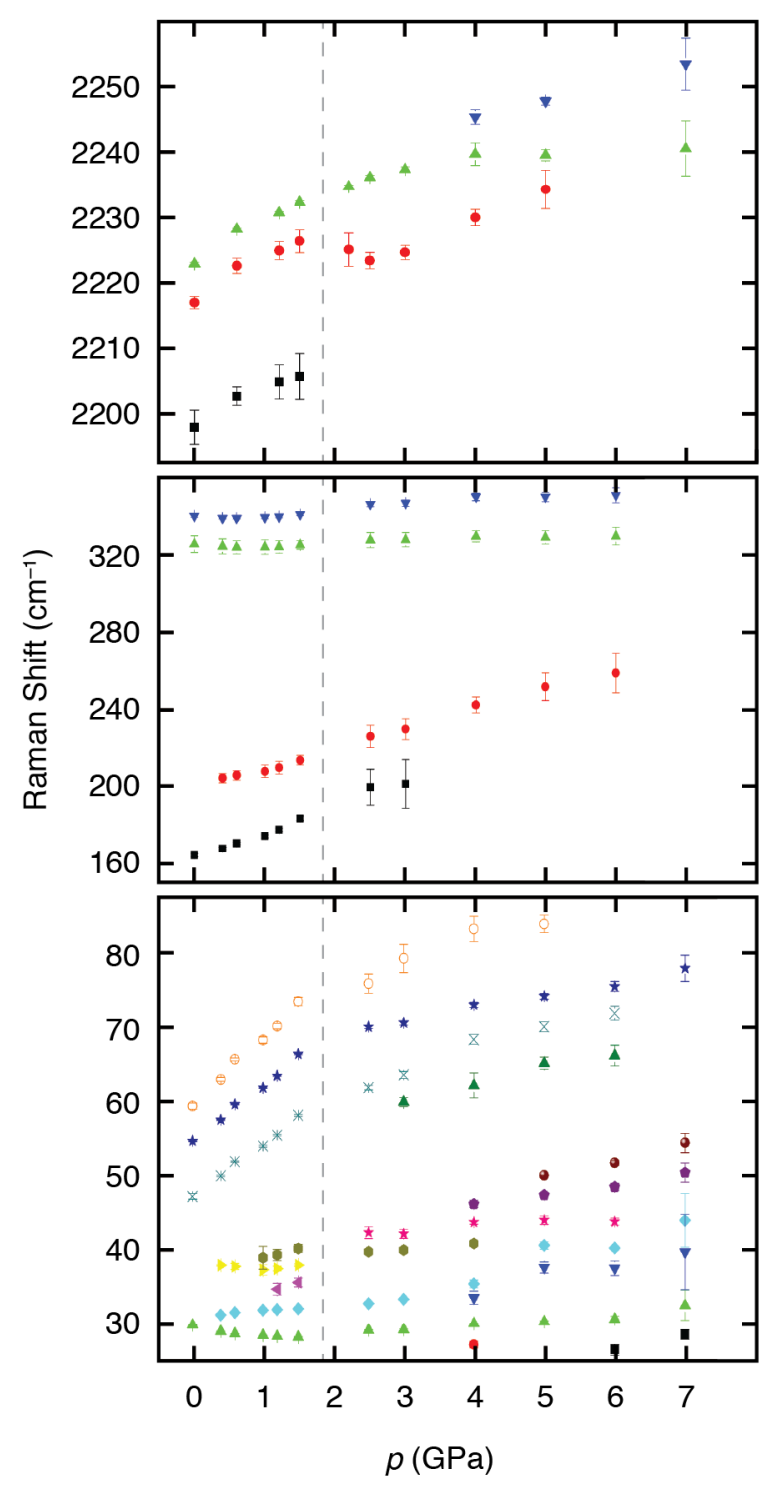

Figure S11: Pressure dependence of the Raman vibrational frequencies over the range $0<$ $p<7 \mathrm{GPa}$. The approximate position of the $\mathrm{I} / \mathrm{II}$ phase transition is indicated by a dashed vertical line. 


\section{References}

(S1) Katz, M. J., Ramnial, T., Yu, H.-Z. \& Leznoff, D. B. Polymorphism of $\mathrm{Zn}\left[\mathrm{Au}(\mathrm{CN})_{2}\right]_{2}$ and its luminescent sensory response to $\mathrm{NH}_{3}$ vapor. J. Am. Chem. Soc. 130, 10662-10673 (2008).

(S2) Klotz, S., Chervin, J.-C., Munsch, P. \& Marchand, G. L. Hydrostatic limits of 11 pressure transmitting media. J. Phys. D: Appl. Phys. 42, 075413 (2009).

(S3) Angel, R. J. Absorption corrections for diamond-anvil pressure cells implemented in the software package Absorb6.0. J. Appl. Crystallogr. 37, 486-492 (2004).

(S4) Angel, R. J. Average 2.22 (2011). URL http: / / www. rossangel.com/.

(S5) Sheldrick, G. M. A short history of SHELX. Acta Crystallogr. D46, 112-122 (2008).

(S6) Cosier, J. \& Glazer, A. M. Oxford Cryosystems CryoStream. J. Appl. Crystallogr. 19, 105-107 (1986).

(S7) Altomare, A. et al. SIR 92-a program for automatic solution of crystal structures by direct methods. J. Appl. Crystallogr. 27, 435 (1994).

(S8) Betteridge, P., Carruthers, J., Cooper, R. I., Prout, K. \& Watkin, D. J. CRYSTALS version 12: software for guided crystal structure analysis. J. Appl. Crystallogr. 36, 1487 (2003).

(S9) Prince, E. Mathematical Techniques in Crystallography and Materials Science. (Springer-Verlag, New York, 1982).

(S10) Flack, H. On enantiomorph-polarity estimation. Acta Crystallogr. A 39, 876-881 (1983).

(S11) Thompson, A. L. \& Watkin, D. J. CRYSTALS enhancements: absolute structure determination. J. Appl. Crystallogr. 44, 1017-1022 (2011).

(S12) Mao, H. K., Xu, J. \& Bell, P. M. Calibration of the ruby pressure gauge to $800-k b a r$ under quasi-hydrostatic conditions. J. Geophys. Res. 91, 4673-4676 (1986).

(S13) Hammersley, A. P. FIT2D: An introduction and overview. Tech. Rep. ESRF97HA02T, ESRF (1997).

(S14) Hammersley, A. P., Svensson, S. O., Hanfland, M., Fitch, A. N. \& Häusermann, D. Twodimensional detector software: From real detector to idealised image or two-theta scan. High Press. Res. 14, 235-248 (1996).

(S15) Coelho, A. A. TOPAS-Academic, version 4.1 (Computer Software). Coelho Software, Brisbane.

(S16) Goodwin, A. L. et al. Colossal positive and negative thermal expansion in the framework material $\mathrm{Ag}_{3}\left[\mathrm{Co}(\mathrm{CN})_{6}\right]$. Science 319, 794-797 (2008).

(S17) Rietveld, $\mathrm{H}$. Line profiles of neutron powder-diffraction peaks for structure refinement. Acta Crystallogr. 22, 151-152 (1967).

(S18) Coelho, A. A. TOPAS v2.0: General profile and structure analysis software for powder diffraction data. Karlsruhe (2000).

(S19) Goodwin, A. L., Keen, D. A. \& Tucker, M. G. Large negative linear compressibility of $\mathrm{Ag}\left[\mathrm{Co}(\mathrm{CN})_{6}\right]$. Proc. Natl. Acad. Sci. 105, 18708-18713 (2008).

(S20) Ogborn, J. M., Collings, I. E., Moggach, S. A., Thompson, A. L. \& Goodwin, A. L. Supramolecular mechanics in a metal-organic framework. Chem. Sci. 3, 3011-3017 (2012).

(S21) Birch, F. Finite elastic strain of cubic crystals. Phys. Rev. 71, 809 (1947).

(S22) Cliffe, M. J. \& Goodwin, A. L. PASCal: A principal-axis strain calculator for thermal expansion and compressibility determination. J. Appl. Crystallogr.. 45, 1321-1329 (2012).

(S23) Grima, J. N., Attard, D. \& Gatt, R. Unusual thermoelastic properties of methanol monohydrate. Science 331, 687-688 (2011).

(S24) Barnes, D. L., Miller, W., Evans, K. E. \& Marmier, A. Modelling negative linear compressibility in tetragonal beam structures. Mechan. Mater. 46, 123-128 (2012). 